\title{
Numerical simulation of a steel weld joint and fracture mechanics study of a Compact Tension Specimen for zones of weld joint
}

\author{
Ahmed Bensari \\ University of Sidi Belabbes, LMSR Laboratory, 22000, Sidi Belabbes, Algeria \\ abmed.bensari@yahoo.com,bttp://orcid.org/0000-0001-2345-6789 \\ El Bahri Ould Chikh \\ University of Mascara, LSTE Laboratory, 29000, Mascara, Algeria. \\ b.ouldchikb@univ-mascara.dz, bttp://orcid.org/0000-0002-2345-6790 \\ Benattou Bouchouicha, Malika Tirenifi \\ University of Sidi Belabbes, LMSR Laboratory, 22000, Sidi Belabbes, Algeria \\ benattou_b@yahoo.fr,bttp://orcid.org/0000-0003-2345-6791 \\ ternifi.malika@yahoo.fr,.bttp://orcid.org/0000-0004-2345-6792
}

\begin{abstract}
To evaluate the integrity of a structure is to prove its ability to perform its mechanical functions for all modes of loading, normal or accidental, and throughout its life. In the context of the nuclear safety, for the most important structures such as the tank or the primary circuit, the presence of a degradation in these structures grouping several aspects, such as cracks created during welding. We seek then, to show the mechanical resistance for this defect mode. It also seeks to fit the mechanical resistance of a structure in the presence of a crack when the defects have been detected during an inspection. In this context, the fracture mechanics provides the necessary tools to analyze cracked components. Its purpose is to establish a fracture criterion to foreordain the loading margins in normal or accidental operating conditions. Each type of rupture must be the subject of a specific characterization.
\end{abstract}

KEYwORDS. Welding; Residual Stress; Energy Release Rate; Stress Intensity Factor.

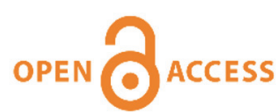

Citation: Bensari, A., Ould Chikh, E.B., Bouchouicha B., Tirenifi M, Title title title, Frattura ed Integrità Strutturale, 47 (2019) 1729.

Received: 13.07 .2018

Accepted: 28.10 .2018

Published: 01.01.2019

Copyright: (C) 2019 This is an open access article under the terms of the CC-BY 4.0, which permits unrestricted use, distribution, and reproduction in any medium, provided the original author and source are credited.

\section{INTRODUCTION}

elding processes lead to changes in microstructure, residual stresses, and distortions that play an essential role in the mechanical strength of assemblies. These stresses and deformations come mainly from the temperature gradients and any phase transformations that may occur during the process. The contributions of welding modeling are at the level of: 
- Feasibility studies of a process to identify any structural misalignment or to optimize the welding sequence;

- Evaluation of the mechanical strength of welded joints.

The feasibility of a process is judged in terms of residual distortions. Their evaluation requires simulations on the structure and including all the welded joints.

The evaluation of the mechanical strength is mainly based on the knowledge of the microstructure and the residual stresses. The analyzes are often qualitative, but we can go further even if published studies are relatively few [1,2].

The evaluation of a welded structure requires characteristic properties of materials through by using of small-sized specimens extracted from the welded structures [3, 4], searches were conducted by Muránsky et al. [5] where he concluded that the residual stresses maintained remain significant, reaching $100 \mathrm{MPa}$. They are sufficient to produce a stress intensity factor in mode I from 5 to $6 \mathrm{MPa} \cdot \mathrm{m}^{1} / 2$. From this, he shows us that finite element simulation techniques can provide a reliable and validated prediction in CT specimens. Residual stresses are the balancing efforts that exist in a structure without the presence of external loading. They can be produced from many sources such as fabrication, mechanical loading and most suitable for this study, by welding [6].

Bouchard [7] gives recent results on residual welding stresses. They include the results of 19 finite element analyzes and five sets of measurements with different methods. They were obtained by welding a stainless-steel plate.

The multi-pass welding processes of industrial structures are probably the most difficult of all welding processes from numerical modeling. In fact, to the difficulties already mentioned above, concerning the size of numerical models, in particular, we must add those related to the multiplicity of welding passes. The computation times, firstly, increase proportionally to the number of passes and quickly become unreasonable, which led to looking for grouping methods of the passes [8]. Moreover, the multiplicity of the thermal cycles seen by the material requires even finer modeling behavior and a corresponding validation phase. A numerical simulation was done by Baup [9]. The test presented here concerns a disk with a radius of $160 \mathrm{~mm}$ and a thickness of $5 \mathrm{~mm}$ made of steel of the type 16MND5 [10]. Elastic-plastic and elasticviscoplastic modeling of the disc is carried out using the model of behavior proposed by Bergheau and Leblond [11, 12].

Baup [9] notes that elastic-plastic simulation strongly over-estimates, whereas simulation elastic-viscoplastic gives an evolution very close to the experimental results. These simulations showed that, on this test, only modeling including the viscous effects made it possible to find correct residual deformations. Similar results were also obtained by Vincent [13]. On the other hand, the influence of the viscous effects on the residual stresses seems marginal. This is probably due by the plasticization, which appears at low temperature during the final cooling, erases almost totally the memory of the viscoelastic effects occurring at high temperature.

A weld joint consists of three micro-structural areas of the material: heat-affected zone (HAZ), fusion metal, and base metal. The three zones of the weld joint exhibit different mechanical behaviors such as mechanical properties, resilience, and hardness. Among these mechanical properties, the stress intensity factor $(\mathrm{K})$ which was proposed in 1957 by Irwin to characterize the stress field existing at the edges of the crack-tip. The J-integral was envisaged in 1968 by Rice to describe the elastic-plastic intensity of the fields at the crack-tip. The CTOD (Crack Tip Opening Displacement) was envisioned in 1963 by Wells to provide like a parameter of fracture of engineering and can be employed like $\mathrm{K}$ or $\mathrm{J}$ in the practical relevance. Various experimental techniques were developed to measure these last parameters to depict the breaking strength of materials $[14,15,16,17]$.

An experimental study of the fracture toughness was established by Mehta [18] to evaluate K and J of steel SA 516 Gr.70. The value of KIc found for the material of SA-516 Gr.70 is $129.37 \mathrm{MPa} \cdot \mathrm{m}^{1 / 2}$ and the critical energy release rate GIc for the crack growth, calculated for the SA-516 Gr.70 is $72.59 \mathrm{~kJ} / \mathrm{m} 2$. The J-integral found for steel SA-516 Gr.70 is $211.08 \mathrm{~N} / \mathrm{mm}$.

The purpose of this article is to study the temperature distribution and the residual stresses generated during welding by a numerical simulation for two different types of chamfers X-Groove and V-Groove. Moreover, this article was enriched by a numerical study to identify the $\mathrm{K}$ and $\mathrm{G}$ parameters for different crack lengths. Finally, we finish our work with a numerical study to describe the fracture behavior of the material for the three zones of the weld. The material chosen for this study is low carbon steel SA-516 Gr 70, which is the material commonly used for the manufacture of pressure vessels.

\section{Presentation of THE Material}

he material used is low carbon steel SA-516 Grade 70, It is mostly used for the construction of pressure vessels [19], which will help the investigation of the various phenomena that occur during welding with involving the precipitation phenomenon. The material model (PLASTIC_KINEMATIC) has been introduced with the mechanical properties coming from ASME, Section-II, Materials Properties, Part-D. 


\begin{tabular}{rcccccccccccc}
\hline Element (\%) & $\mathrm{C}$ & $\mathrm{S}$ & $\mathrm{P}$ & $\mathrm{Si}$ & $\mathrm{Mn}$ & $\mathrm{Ni}$ & $\mathrm{Cr}$ & $\mathrm{Mo}$ & $\mathrm{Cu}$ & $\mathrm{Ti}$ & $\mathrm{V}$ \\
SA 516 Gr.70 & 0.16 & 0.005 & 0.013 & 0.44 & 1.45 & 0.08 & 0.07 & 0.008 & 0.038 & 0.004 & 0.1 \\
\hline
\end{tabular}

Table 1: Chemical compositions.

\begin{tabular}{ccccccc|ccc}
\hline \multicolumn{1}{c|}{ Mechanical properties } & \multicolumn{2}{c}{ Thermal Properties } \\
Material & $\begin{array}{c}\text { Yield } \\
\text { Strength } \\
(\mathrm{MPa})\end{array}$ & $\begin{array}{c}\text { Tensile } \\
\text { Strength } \\
(\mathrm{MPa})\end{array}$ & $\begin{array}{c}\text { Elongation } \\
\text { at Break } \\
(\%)\end{array}$ & $\begin{array}{c}\text { Modulus of } \\
\text { Elasticity } \\
(\mathrm{GPa})\end{array}$ & $\begin{array}{c}\text { Poissons } \\
\text { Ratio }\end{array}$ & $\begin{array}{c}\text { Bulk } \\
\text { Modulus } \\
(\mathrm{GPa})\end{array}$ & $\begin{array}{c}\text { Shear } \\
\text { Modulus } \\
(\mathrm{GPa})\end{array}$ & $\begin{array}{c}\text { Specific } \\
\text { Heat } \\
\text { Capacity } \\
\left(\mathrm{J} / \mathrm{g}-{ }^{\circ} \mathrm{C}\right)\end{array}$ & $\begin{array}{c}\text { Thermal } \\
\text { Conductivity } \\
(\mathrm{W} / \mathrm{m}-\mathrm{K})\end{array}$ \\
SA 516 Gr.70 & 355 & $485-620$ & 21 & 200 & 0.3 & 160 & 80 & 0.44 & 36.3 \\
\hline
\end{tabular}

Table 2: Mechanical properties and thermal properties at room temperature.
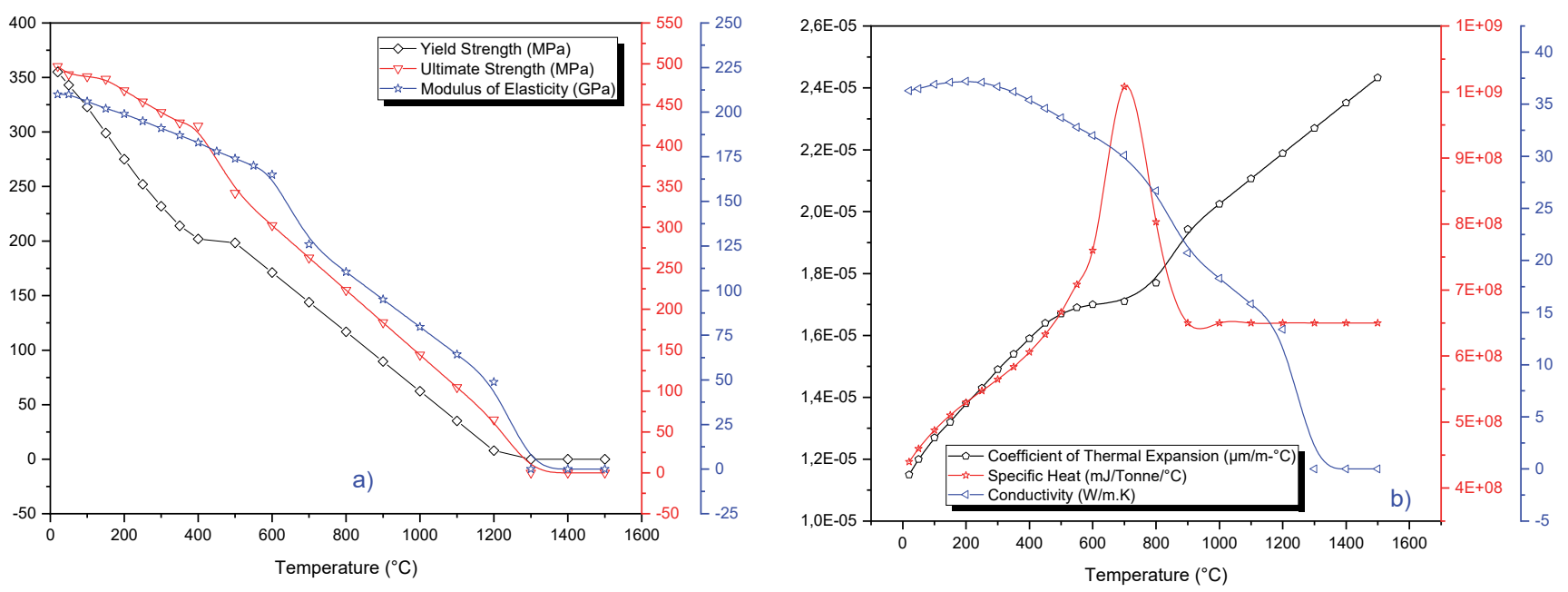

Figure 1: The variation of properties as a function with temperature. (a) Mechanical properties and (b) Thermal properties.

The values of these parameters have been obtained by an extrapolation and interpolation from the extracted values of ASME, the density of the carbon steel was taken as its ambient value of $7850 \mathrm{~kg} / \mathrm{m} 3$ over the normally experienced temperature range in a building fire [20]. We have been proposed that the poisson ratio remains constant for all temperature values.

\section{METHODOLOGY OF NUMERICAL SIMULATION}

7 ypical examples of simulations using elastic-plastic models are provided by the studies of Bergheau and Leblond $[11,12]$. In contrast, few simulations have used elastic-viscoplastic models. The reason why elastic-viscoplastic effects are disregarded in most welding simulations is that the duration of welding processes is quite short, so that it is generally thought to be insufficient for significant creep to occur. In the present study, a thermal elastic-plastic finite element procedure was employed to simulate the thermo-mechanical response of welding problem. The specimens used in this study are plates of $150 \mathrm{~mm}$ in length and $15 \mathrm{~mm}$ in thickness for the two types of chamfers; X-Groove and VGroove with four passes as mentioned in Fig. 2.

The two different weld specimens were analyzed using the Abaqus AWI 2D Graphical User Interface (GUI) plug-in. The weld specimens were produced by a mechanised computer-controlled welding system, which adjusted the speed, feed and energy across the specimens. The FE models were rapidly constructed using the AWI plug-in in Abaqus/CAE. The 
preprocessing for mesh generation and material section assignments were carried out in Abaqus/CAE. The welding parameter definitions were generated in the AWI plug-in to complete the preprocessing [21].

The first step for the entire model uses the *MODEL CHANGE* flag to delete all the weld beads. Then each bead is sequentially filed in four steps for the thermal model. The four steps are:

1. Apply Torch: During this step, a boundary condition is applied to ramp the temperature at the edges of the weld cavity where the weld bead is to be deposited up to the specified melting temperature (in this case $1500^{\circ} \mathrm{C}$ ).

2. Torch Hold: During this step, the temperature boundary condition at the edges of the weld cavity is held fixed at $1500^{\circ} \mathrm{C}$ and heat is allowed to soak out into the rest of the model. A FORTRAN subroutine (created automatically by the AWI plug-in) is used to set the length of this step and, therefore, control the amount of heat transferred into the model. The subroutine monitors the temperature at 'sensor' nodes that are located around the edge of the weld bead; when these nodes reach the target temperature of $750^{\circ} \mathrm{C}$, the step is ended.

3. Torch Pause: During this step, the elements within the weld bead that is being deposited are activated (at an initial temperature of $1500^{\circ} \mathrm{C}$ ) and the fixed temperature boundary condition around the edge of the bead is removed to allow heat to soak through the model.

4. Cool-down: This step represents the model between weld passes when the heat from the most recent pass of the weld torch soaks through the component. During manufacture of the actual components an inter-pass temperature of $125^{\circ} \mathrm{C}$ for the both FE models. To account for this, the FORTRAN subroutine was again used to control the end of the step, with the target temperature set to $125^{\circ} \mathrm{C}$ depending on the model for all the passes except for the final one, for which $21^{\circ} \mathrm{C}$ was applied for the both models. The V-Groove and X-Groove thermal model had 17 steps for 4 weld beads.
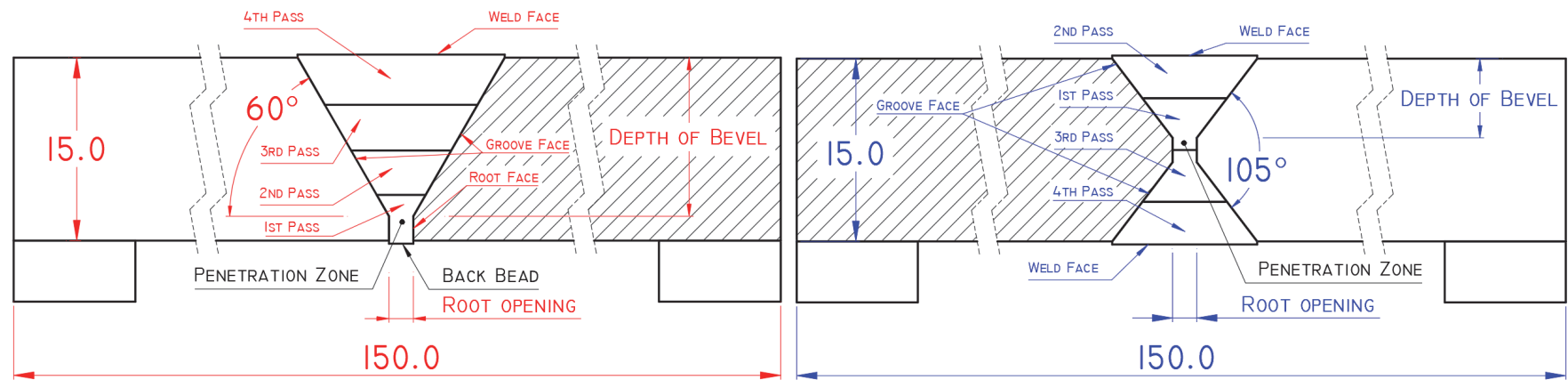

Figure 2: the schema and the dimensions of the welded plates.

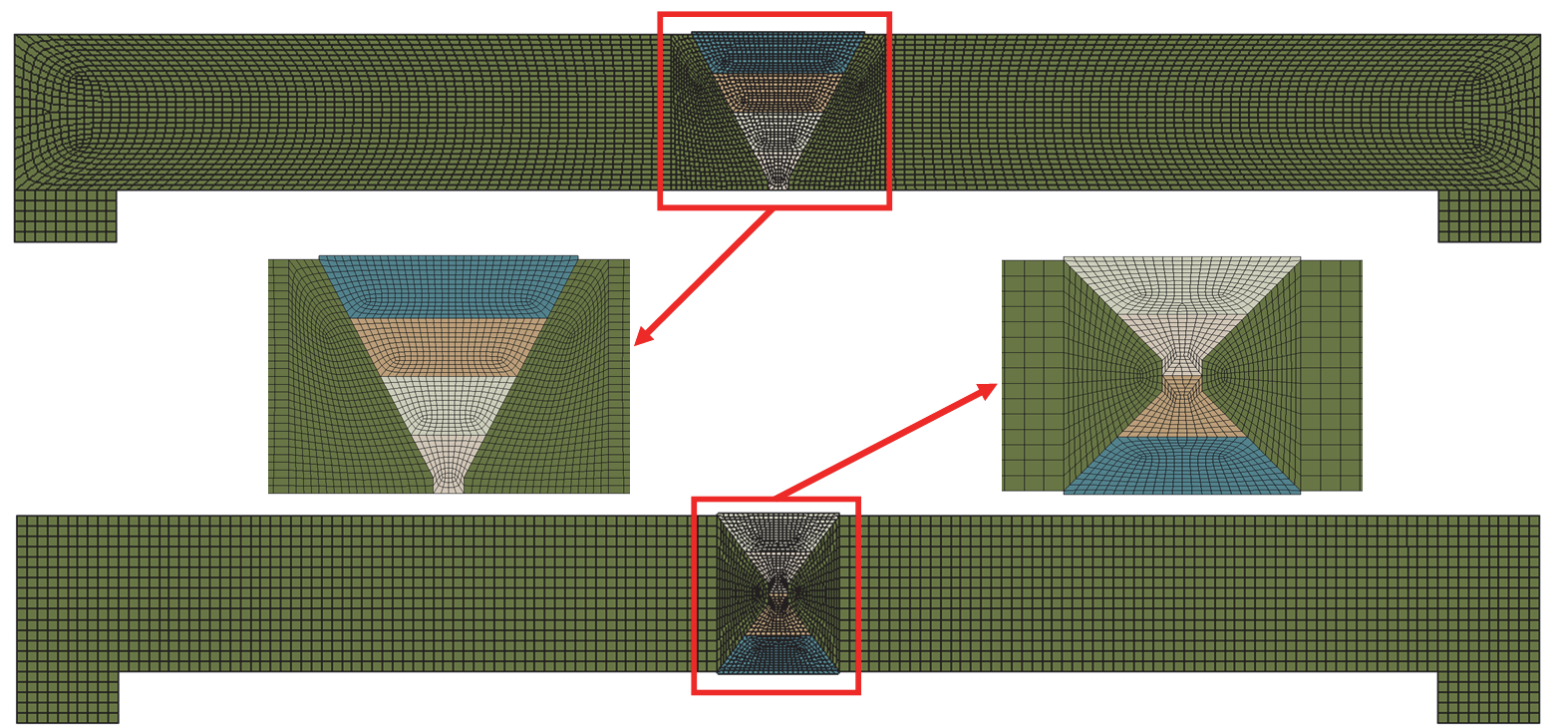

Figure 3: The mesh used for the simulation.

The mesh (see Fig. 3) consists of 6348 elements and 6544 nodes for the plate welded with V-Groove, 3652 elements and 3839 nodes for the plate welded with X-Groove, with a refinement in all the passes of welding. 
The thermal and structural input decks were written out by the AWI plug-in; however, modifications were made to the structural input deck, these included changing the elements to generalised plane strain, *ELEMENT, TYPE $=[C P E G 8 R$, CPEG6], creating a node set of all the model nodes for PWHT, *NSET, NSET=name, adding a reference point for the generalised plane strain elements *NODE, applying idealised boundary conditions *BOUNDARY, OP=NEW, and changing the *OUTPUT, FIELD, FREQUENCY=number, flag results to reduce the size of the output database file.

The structural input deck included plastic material properties, *PLASTIC, HARDENING=KINEMATIC with *CREEP, $\mathrm{LAW}=\mathrm{TIME}$ and $*$ ANNEAL TEMPERATURE set at $\mathrm{T}_{\mathrm{m}}$ for both the base and weld materials.

\section{RESULTS AND DISCUSSION}

$\mathrm{I}$ $\mathrm{n}$ fusion welding, a source of energy is necessary to cause the required melting of the materials to be joined. That source is usually chemical or electrical. Not all of that heat contributes to creating melting to produce the weld. Some are conducted away from the point of deposition, raising the temperature of material surrounding the fusion zone (FZ) and causing unwanted metallurgical and geometric changes. This surrounding region is called the heat-affected zone. The temperature distribution for both types of welding, when the heat source is at the mid-span, a tiny area ahead of the heat source is preheated during its motion along the weld line. Temperature around the heat source exceeds $1500^{\circ} \mathrm{C}$ indicating melted material in the fusion zone (FZ) for the four passes. Heat generated by the electrode is gradually conducted to all directions of the weld.
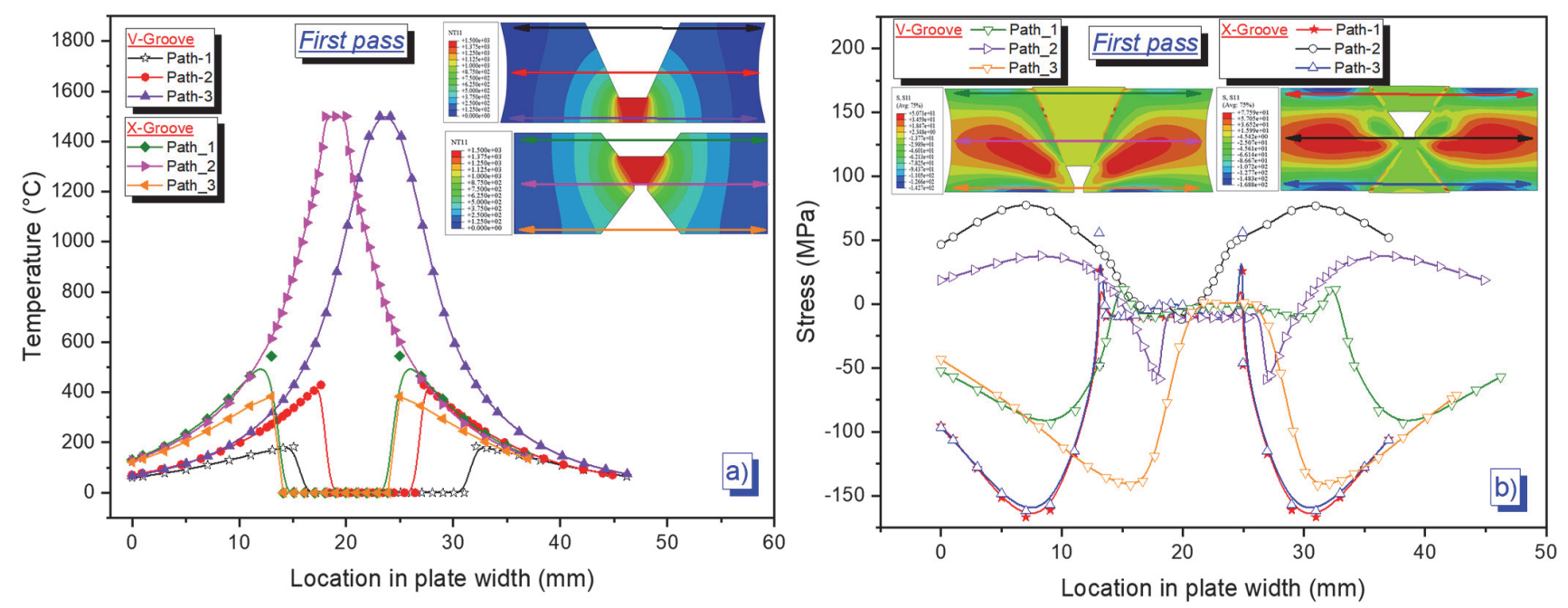

Figure 4: First pass. a) Temperature distribution on location plate width. b) Stress S11 distribution on location plate width.

Thermal cycles (temperature curves) can be determined for paths distributed progressively. Temperature-paths traces for three locations are shown in Figs. 4a-5a-6a and 7a, with the following observations:

- The maximum temperatures, reaching the $1500{ }^{\circ} \mathrm{C}$ in the fusion zone for the four passes.

- The maximum temperatures, decrease with increasing distance from the source, every curve shows that temperature returns asymptotically to ambient.

- The peak temperature separates the heating portion of the thermal welding cycle from the cooling part and expresses the fact that points closest to a weld are already cooling, while points farther away are still undergoing heating. This phenomenon explains certain aspects of phase transformations that go on in the heat-affected zone, as well as differential rates and degrees of thermal expansion and contraction that lead to thermally induced stresses and, possibly, distortion.

- The size and, primarily, the shape of the melt region in a fusion weld affects the mechanics and kinetics of solidification and, therefore, the structure and properties of the resulting weld. The shape and, especially, the size of the weld pool (Fig. 7a), along with the size and shape of the surrounding heat-affected zone, also affects the thermally induced stresses that act on the weld, leading to the formation of defects or residual stresses or distortion. The size and, to a lesser degree, the shape of the heat-affected-zone influences overall weld performance.

The residual stresses have a complicated dependence on many variables, including the geometry of the structure, temperature-dependent thermal and mechanical properties of the base and weld metals, the sequencing in multi-pass 
welding scenarios, inter-pass temperature conditions, the boundary constraints on the parts being welded, and the energy input from the heat source.

Thermal cycles (temperature curves) can be determined for paths distributed progressively. Temperature-paths traces for three locations are shown in Figs. 4a-5a-6a and 7a, with the following observations:

- The maximum temperatures, reaching the $1500{ }^{\circ} \mathrm{C}$ in the fusion zone for the four passes.
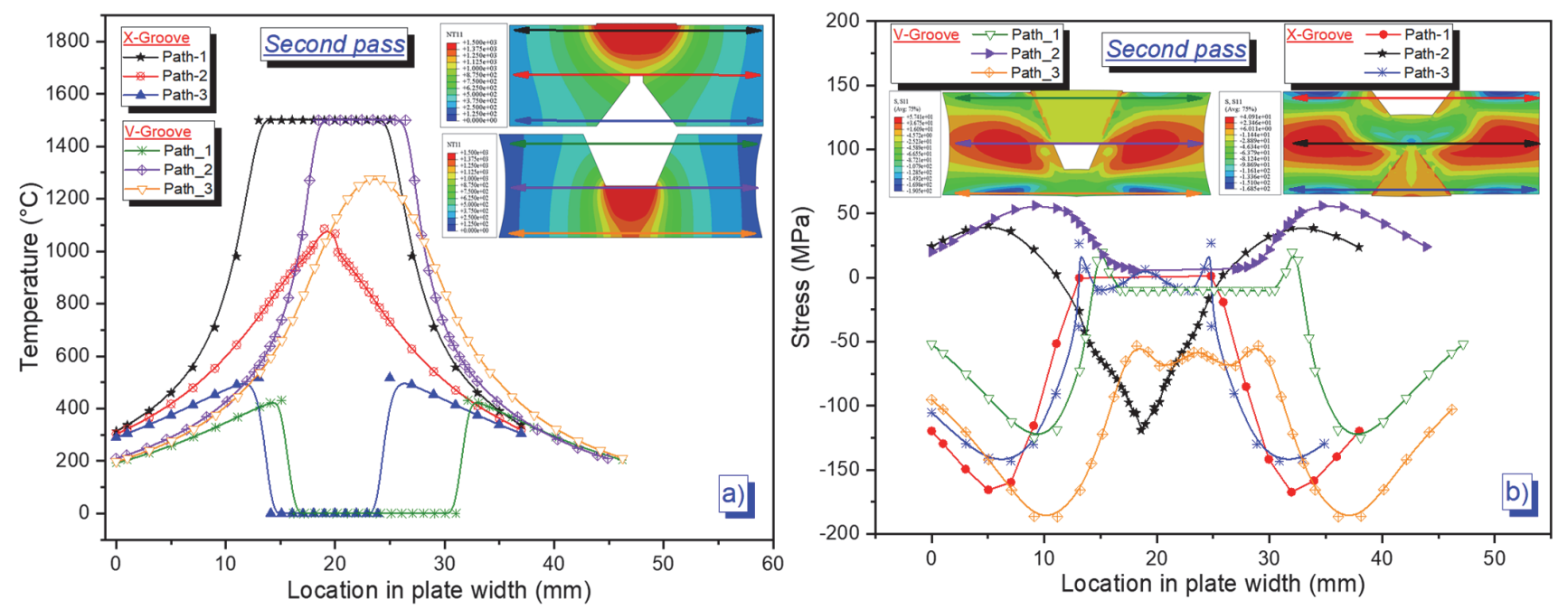

Figure 5: Second pass. a) Temperature distribution on location plate width. b) Stress S11 distribution on location plate width.

The distribution of stresses in the x-direction, $\sigma_{11}$, at path 1 , path 2 and path 3 is shown in Figs. 4b-5b-6b and $7 \mathrm{~b}$ for the tow type of groove.
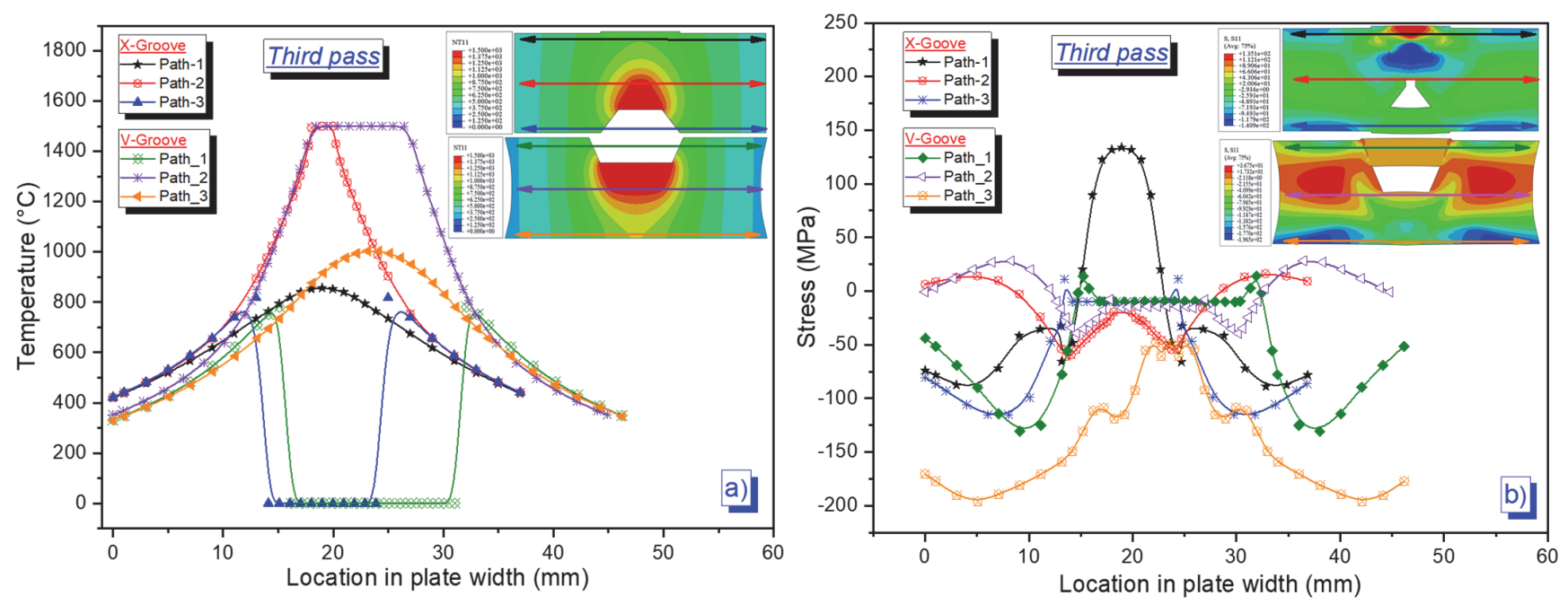

Figure 6: Third pass. a) Temperature distribution on location plate width. b) Stress S11 distribution on location plate width.

Stresses in regions immediately below the arc and weld pool are almost zero because molten metal cannot support a load (path 1 for X-Groove and path 2 for V-Groove, Fig. 5b. Stresses in the heat-affected region on either side of the weld pool, however, do exist and are compressive because thermal expansion in these very hot regions is restrained by surrounding metal at a lower temperature, of higher strength, and without having experienced similar expansion. The limit of these compressive stresses is set by the yield strength of the metal in the heat-affected region. Where the temperature is the highest, which is nearest to the fusion zone, the yield strength is lowest. The yield strength increases with increasing distance from the weld pool, so the compressive residual stress increases to its peak level.

At some point away from the weld line, tensile stresses will arise to balance the compressive stresses induced by thermal expansion. This is essential for the system or weldment to be in mechanical equilibrium. 
As it can be observed, the residual stress profiles are approximately symmetric for all welding conditions from the centerline. The residual stress distributions showed that the peak of compressive stress coincided near the centerline with a peak value of approximately 75-200 MPa, Furthermore, the type of residual stress was compressive inside the FZ and HAZ for almost passes. However, the residual stress and temperature decreased within the base metal. The residual stress for all passes was comprehensive far from the centerline toward the base metal. When the distance to the weld line increases, the welding effect on the final residual stress is small. The manufacturing stress will then have more influence on the last stress field.
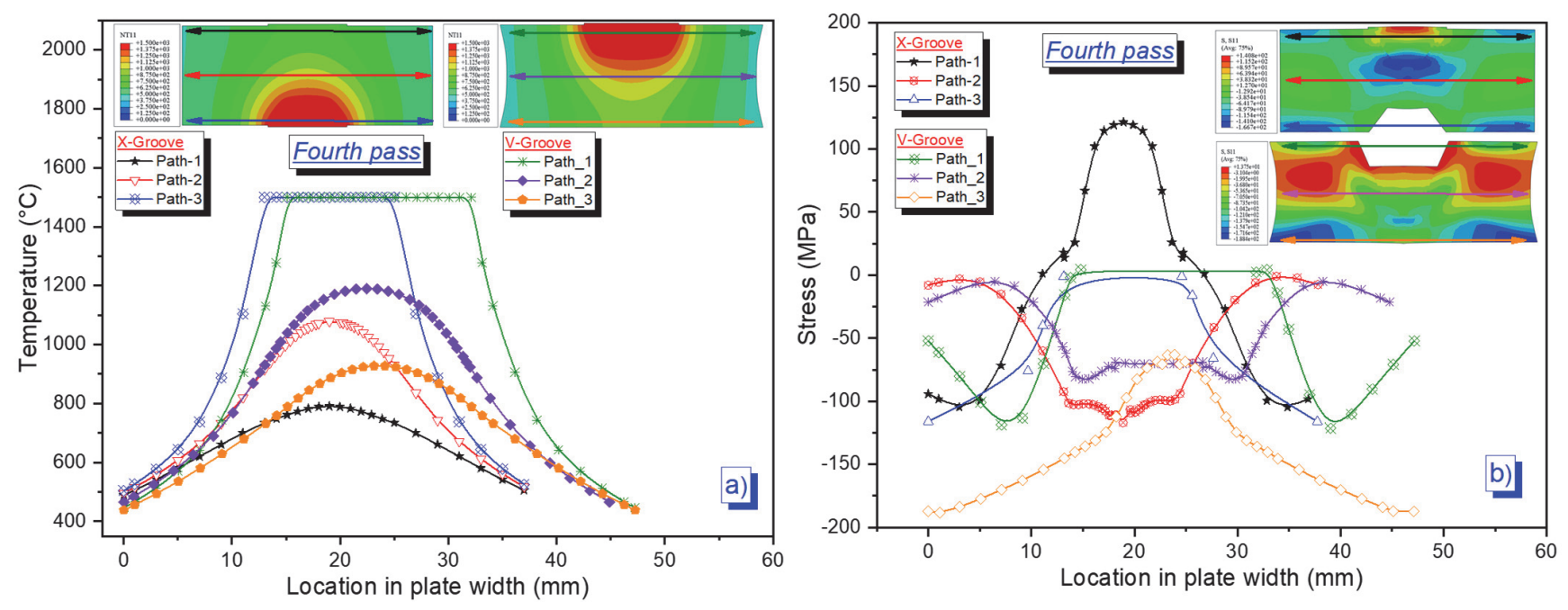

Figure 7: Fourth pass. a) Temperature distribution on location plate width. b) Stress S11 distribution on location plate width.

The residual stress distributions showed that the peak of tensile stress coincided from the centerline with a peak value of approximately $150 \mathrm{MPa}$ with $800{ }^{\circ} \mathrm{C}$ (third and fourth pass-path 1, X-Groove), It is reasonable, just above the 3th pass, we note that there are residual stresses of compression exceed the $140 \mathrm{MPa}$ (blue color), In the weld configuration, stress equilibrium must be maintained, which means that the presence of a tensile residual stress in a component will be balanced by a compressive stress elsewhere in the structure. this explains to us that the structure is in equilibrium.

The effects of distortion as the result of welding (Fig. 8a) are much more obvious than the effects of residual stresses. Recall that distortion during or following welding is the result of unbalanced thermally induced stresses in unrestrained weldments.
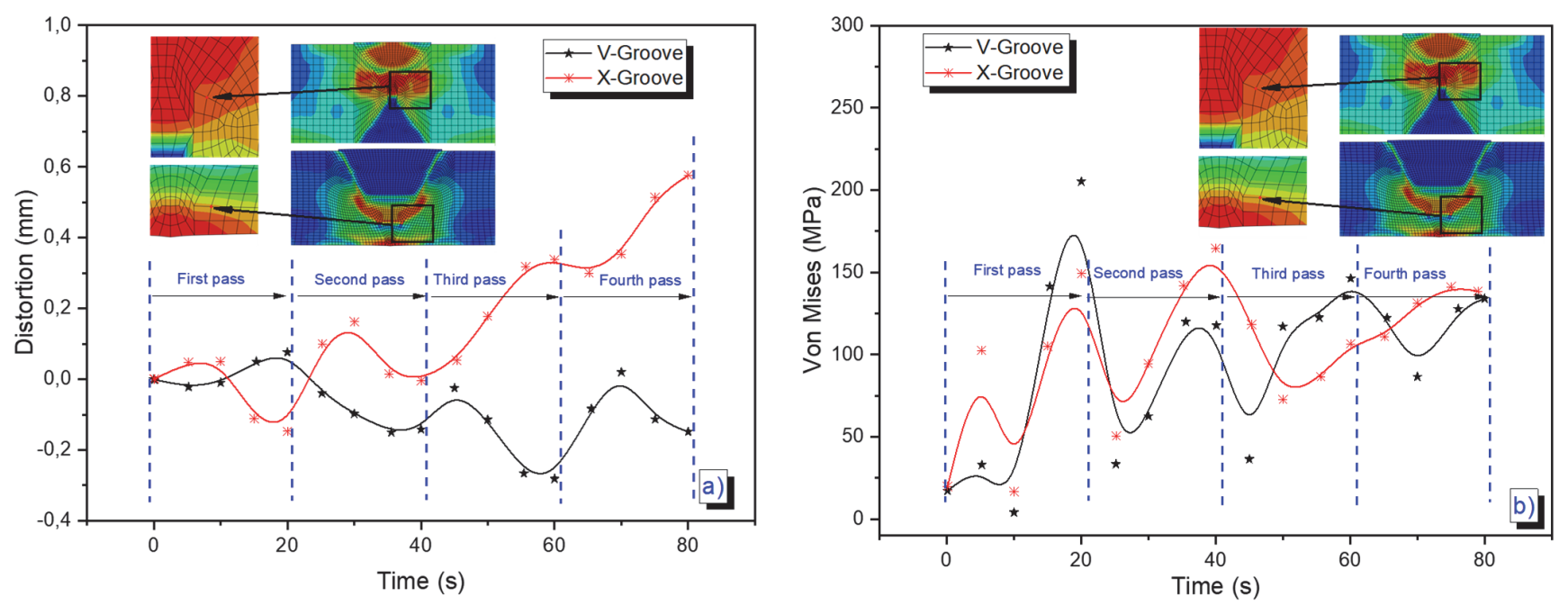

Figure 8: a) Distortion, b) Von Mises stresses of a node during the welding for X, V-Groove.

Fig. $8 \mathrm{~b}$ illustrates the Von Mises stresses of a node during the deposit of the four passes. We have chosen this point, in view of the fact that is located in the HAZ zone, owing to the fact that this zone is the weak in the welding structure. We 
note that the stresses appeared to occur of welding are important in two simulations, they are increased and decreased according to time of welding, the heating characterizes the increase at moment of the deposit of the pass and the reduction is characterized by the cooling of the pass after welding.

\section{EXTRACTION OF SIF AND G VALUES}

I $\mathrm{t}$ is one of the most fundamental and useful parameters in all of fracture mechanics. The stress intensity factor describes the stress state at a crack tip, is related to the rate of crack growth, and is used to establish failure criteria due to fracture. For the compact tension specimen CT75, the SIF (for mode I) can be found analytically by Eq. (1) given below [22]:

$$
\begin{aligned}
& \mathrm{K}_{\mathrm{I}}=\frac{\mathrm{P}}{\mathrm{B} \times \sqrt{\mathrm{W}} \times \mathrm{f}\left(\frac{\mathrm{a}}{\mathrm{W}}\right)} \\
& \mathrm{f}\left(\frac{\mathrm{a}}{\mathrm{W}}\right)=\frac{\left(2+\frac{\mathrm{a}}{\mathrm{W}}\right)}{\left(1-\frac{\mathrm{a}}{\mathrm{W}}\right)^{\frac{3}{2}}} \times\left(0.886+4.64 \times\left(\frac{\mathrm{a}}{\mathrm{W}}\right)-13.32 \times\left(\frac{\mathrm{a}}{\mathrm{W}}\right)^{2}+14.72 \times\left(\frac{\mathrm{a}}{\mathrm{W}}\right)^{3}-5.6 \times\left(\frac{\mathrm{a}}{\mathrm{W}}\right)^{4}\right)
\end{aligned}
$$

One of the first criteria of rupture was established by Griffith [23], He found that the crack could grow if the rate of release of elastic strain energy from its growth exceeded the rate at which surface energy of the crack is increased. This criterion can be written:

$$
\begin{array}{ll}
G_{1}=\left(\frac{1-v^{2}}{E}\right) \times K_{1}^{2} & \text { For the plane strain } \\
G_{1}=\frac{K_{1}^{2}}{E} & \text { For the plane stress }
\end{array}
$$

For our case, we have $G_{1}=\left(\frac{1-v^{2}}{E}\right) \times K_{1}^{2} \quad$ for the plane strain.

However, in welded structures, lack of penetration, lack of fusion will all be regarded as cracks and if the fracture mechanics applies, the fatigue life will de short at the level of residuals stresses in tension in comparison if the residuals stresses are in compression. In this study, we have not considered the residual stress.

Calculations by finite elements were carried out by ABAQUS on nominally identical $C(T)$ specimens. According to standard ASTM E 647 per two thicknesses 7 and $14 \mathrm{~mm}$ (see Fig. 9) for the three zones of welding with a Young modulus of 220,180 and $195 \mathrm{GPa}$ for the base metal, HAZ and fusion zone respectively, with a force of $38,72 \mathrm{KN}$ [18], 31,68 and $34,32 \mathrm{KN}$ [15], where we validated the numerical results by the analytical results. Figs. 10-11 and 12 shows that numerical and analytical results fit very well together.

Figs. 10-11 and 12 shows a perfect accordance between analytical and numerical results is also achieved, furthermore, the SIF in base metal is more prominent than in FZ, and it's bigger in FZ that in HAZ. Even notices for the energy release rate $G$. This difference is due to the mechanical characteristics and the microstructure of the three zones.

\section{EVALUATION OF FRACTURE TOUGHNESS FOR THREE ZONES OF WELD}

7 he X-FEM (Extended Finite Element Method) provides significant benefits in the numerical modeling of crack propagation, the crack geometry in the X-FEM needn't be aligned with the element edges, which offers flexibility and versatility in modeling. The method is based on the enrichment of the finite element model with additional 
degrees of freedom (DOF) that are tied to the nodes of the elements intersected by the crack.

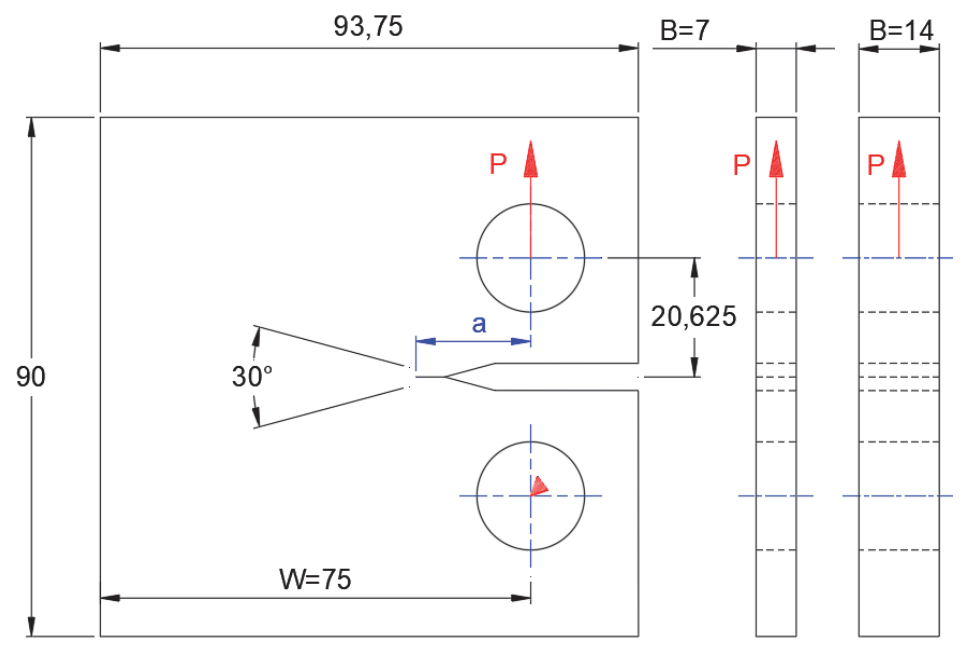

Figure 9: Compact tension Specimen CT75.
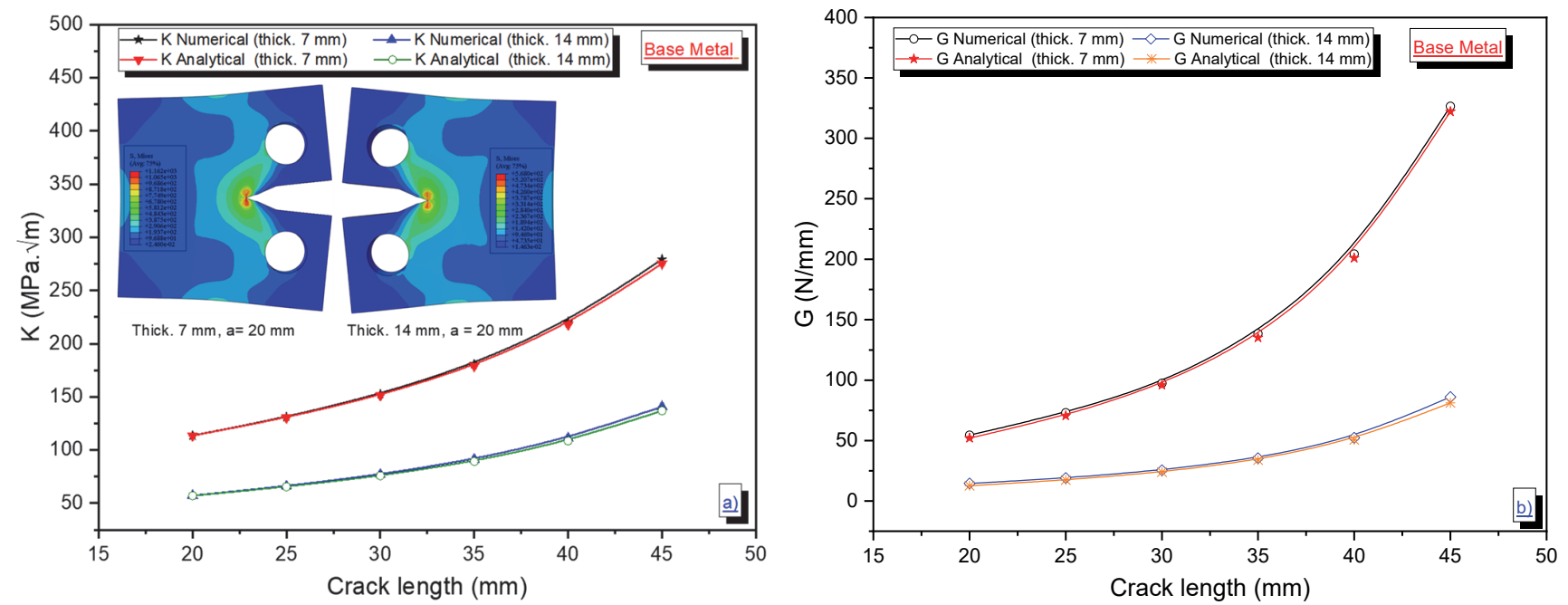

Figure 10: The SIF and $G$ values as a function of crack length for the base metal $(B=7$ and $14 \mathrm{~mm})$.
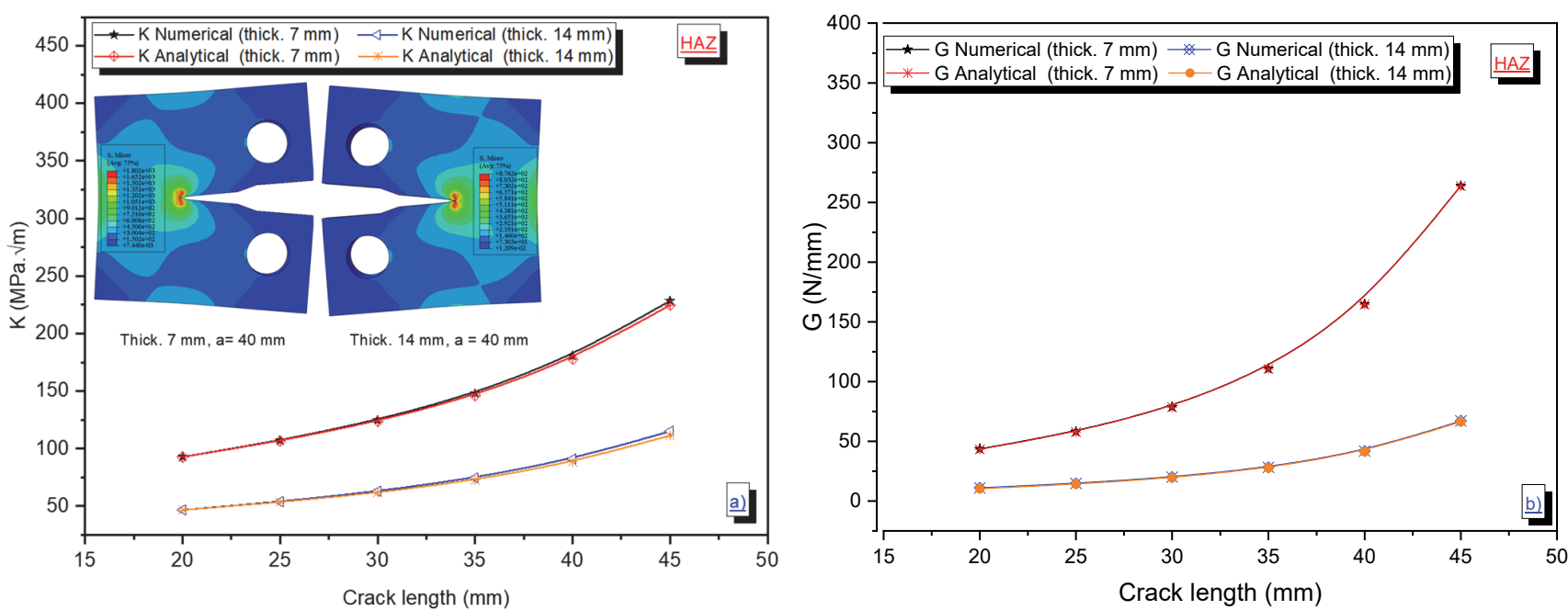

Figure 11: The SIF and $G$ values as a function of crack length for HAZ (B=7 and $14 \mathrm{~mm})$. 

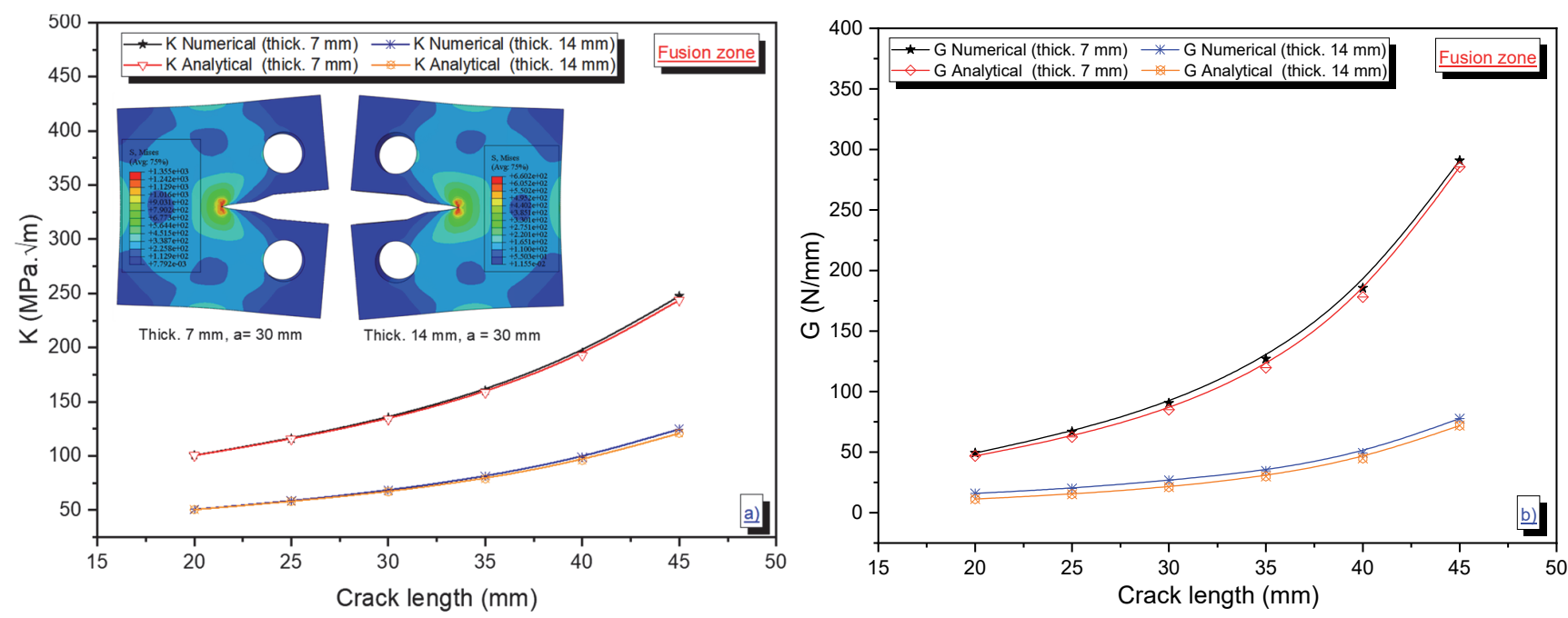

Figure 12: The SIF and $G$ values as a function of crack length for $F Z(B=7$ and $14 \mathrm{~mm})$.

Finite element models of a CT specimen with crack lengths of $\mathrm{a} / \mathrm{W}=0.2$. The $\mathrm{CT}$ specimen modeled is with a standard width, $\mathrm{W}=75 \mathrm{~mm}$, the analyses were performed using the Abaqus finite element package. Three-dimensional plane strain elements, C3D8R, were used, and the total number of elements is approx. 22941 and 46476 nodes, under a loading of $38,72 \mathrm{KN}$ [18], 31,68 and 34,32 KN applied to base metal, HAZ and FZ respectively [15]. The finite element mesh is shown in Fig. 13.

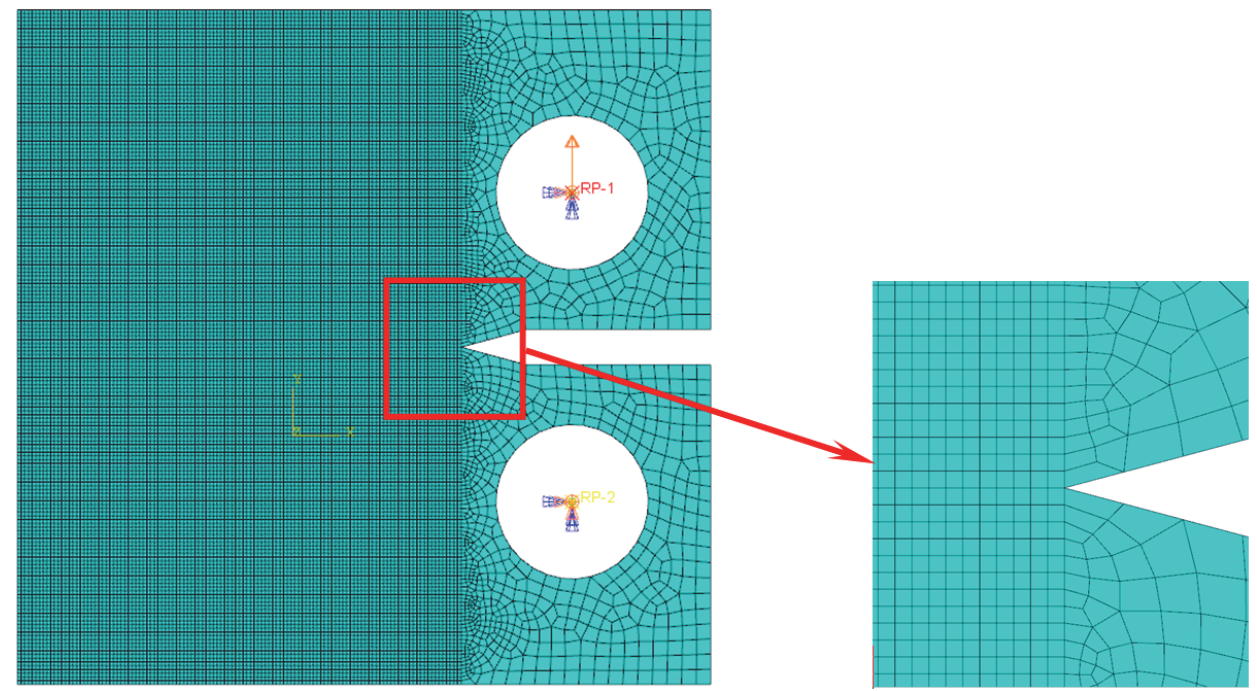

Figure 13: finite element mesh of CT75 (Compact Tension).

After carrying out the numerical fracture tests. The stresses of Von Mises in the base metal are more critical than in FZ, even thing for FZ that in the HAZ (see Fig. 15).

Load-Displacement curves were obtained for all three zones of weld, as shown in Fig. 16. The load value increases with the load line displacement until the crack initiation takes place. As the crack initiates and crack propagation begins, the load value starts falling till the full rupture of specimen.

The value of the load increases with the line of a load of displacement until the starting and propagation of the crack. The ductile tearing is initiated in the middle of the notch through a mechanism of shear. The ductile tear then propagates simultaneously to the edges of the specimen, forming shear lips and in front of the notch.

It is visibly detectable that the curves pursue nearly identical pathway for the crack propagation, but there is a difference for the peak load, this is due to the characteristics of the three zones. 
(a)

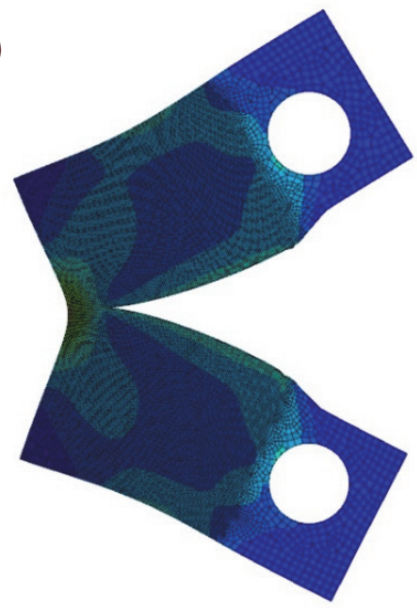

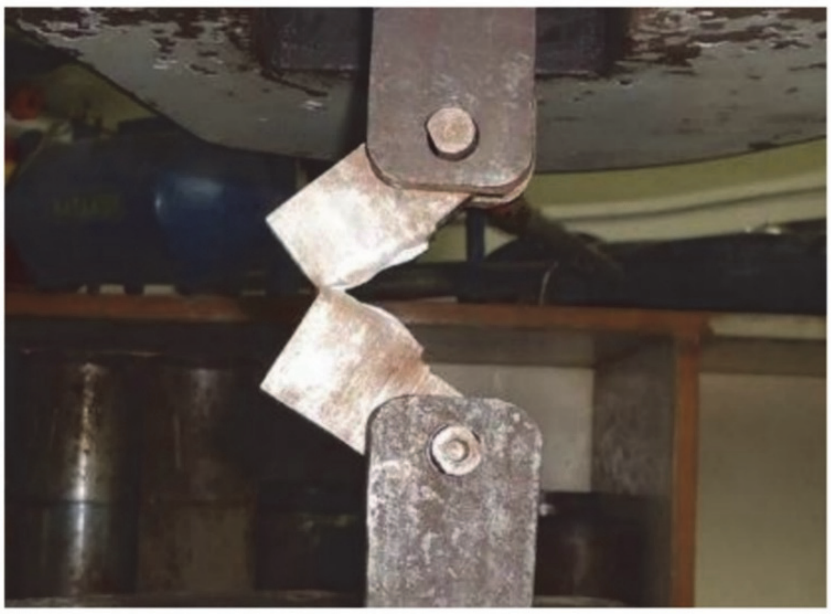

(b)

Figure 14: a) Phenomenon of fracture toughness, b) crack propagation reaches to full rupture [17].

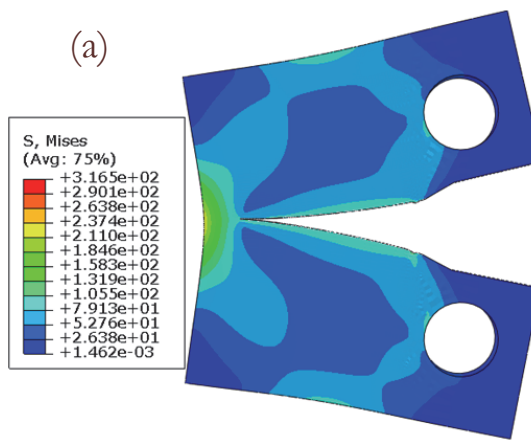

(b)

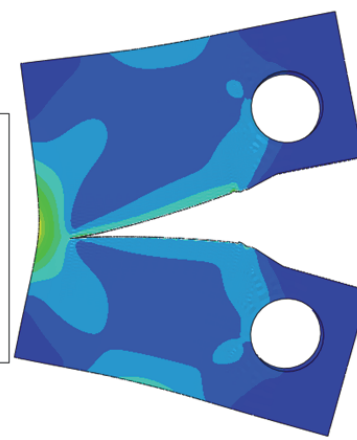

(c)

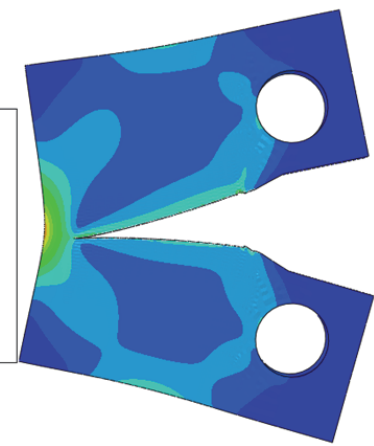

Figure 15: Stresses of Von Mises, a) base metal, b) Fusion zone (FZ), c) Heat affected zone (HAZ).

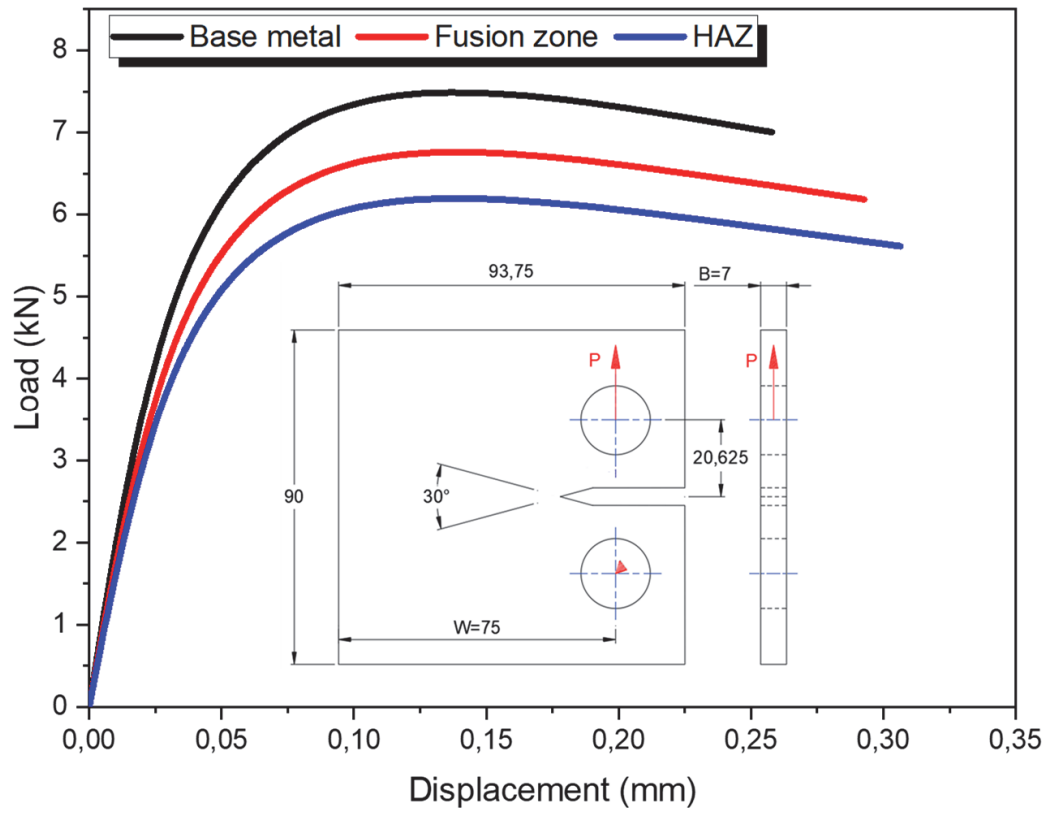

Figure 16: curves of load-displacement for base metal, FZ, and HAZ. 


\section{CONCLUSION}

I $\mathrm{n}$ this paper, we described numerical modeling of the welded joint in steel structural elements; the numerical modeling was focused on stress analysis of butt welds for two chamfers in supporting elements of steel structures. The numerical simulation of the joints of welding is used to predict the distribution of the temperatures occurs of the deposit of the passes of welding, thus to quantify the residual stresses generated during welding. The results of the study suggest that the numerical modeling describes the stress-strain state in welded joints with sufficient precision. The proposed computation procedure could be used in design practice for calculations of the stress-strain state in welded joints.

The severity of heating and cooling associated with the thermal cycles typical of fusion welding processes frequently result in high thermally induced strains and stresses. These can, in turn, lead to severe distortion if the material or structure is free to respond, or to severe residual stresses if the material or structure is restrained. For metals and alloys that undergo phase transformations in the fusion zone or heat affected zone (or both), on cooling, the residual stress pattern is further complicated by dilatational strains. Residual stresses pose more insidious problems with a tendency to reduce breaking strength and increase brittle behavior, alter and, usually, reduce fatigue life, and aggravate corrosion.

Furthermore, a numerical method of analysis can calculate KI and GI of a crack in a three-dimensional model on mode I. For this part, one validated the numerical results by the analytical results of KI and GI. The values of KI and the energy release rate when the mechanical efforts are applied with deferent lengths of the crack are distinct, and it's noticed that KI and GI increase when the length of the crack increases. The sector of the lowest fracture strength is meadows of the line of fusion, in the heat affected zone.

The fracture toughness was carried out by the numerical method for a compact tension specimen CT, thick $7 \mathrm{~mm}$ for the three zones of welding (BM, FZ, and HAZ), The following conclusions can be illustrated:

According to the approach of the linear fracture mechanics, the stress intensity factor (KI) is one of the parameters of characterization of the crack. The stress will be infinite at the point of the crack.

As the zones examined are plastic and hard, KI is not enough the single parameter to indicate the fracture strength. The energy release rate GI is also an important parameter.

For the fracture toughness test, we had a little difference in the peak load for the three zones, but it is visibly that the pathways are nearly identical.

In future research, further application of the numerical simulation of the weld with the existence of a crack, to determine the parameters of the fracture mechanics in considered the residuals stresses.

\section{REFERENCES}

[1] Radaj, D. (2002). Integrated finite element analysis of welding residual stress and distortion, Mathematical Modelling of Weld Phenomena, 6, pp. 469-489.

[2] Devaux, J., Mottet, G., Bergheau, J.M., Bhandari, S. and Faidy, C. (2000). Evaluation of the integrity of PWR bimetallic welds, J. Pressure Vessel Tech, 122(3), pp. 368-373. DOI:10.1115/1.556194.

[3] R6. (2011) Assessment of the integrity of structures containing defects. British Energy Generation Limited. DOI: 10.1016/0308-0161(88)90071-3.

[4] American Petroleum Institute/ASME (2007). Fitness-for-Service, API 579-1/ASME FFS-1, Washington DC, USA.

[5] Muránsky, O., Smith, M.C., Bendeich, P.J., Hosseinzadeh, F. and Edwards, L. (2014). Numerical analysis of retained residual stresses in $\mathrm{C}(\mathrm{T})$ specimen extracted from a multi-pass austenitic weld and their effect on crack growth, Engineering Fracture Mechanics, pp. 40-53. DOI: 10.1016/j.engfracmech.2014.04.008.

[6] Zerbst, U. (2014). Review on fracture and crack propagation in weldments, A fracture mechanics perspective. 132, pp. 200-276. DOI: 10.1016/j.engfracmech.2014.05.012.

[7] Bouchard, P.J. (2008). Combined use of FE-simulations and neutron/X-ray experiments. VDI-Expert Forum.

[8] Bouchard, P.J. (2008). Code characterization of weld residual stress levels and the problem of innate scatter, Int J Pres Ves Piping, 85. pp. 152-65. DOI: 10.1016/j.ijpvp.2007.10.013.

[9] Baup, O. (2001). La simulation numérique du soudage, Développements et validation de méthodes simplifiées et de groupage de passes. Thèse de doctorat, Université d'Aix-Marseille II, France.

[10] Bergheau, J. (2004). Modélisations numériques des procédés de soudage, Technique de l’ingénieur. 
[11] Bergheau, J.M., Vincent, Y., Leblond, J.B. and Jullien, J.F. (2004). Viscoplastic behavior of steels during welding. Science and Technology of Welding and Joining. 9, pp. 232-330. DOI: 10.1179/136217104225021689.

[12] Leblond, J.B., Devaux, J. and Devaux, J.C. (1989). Mathematical modeling of transformation plasticity in steels, I: Case of ideal plastic phases, II: Coupling with strain-hardening phenomena. Int. J. Plasticity, 5, pp. 551-591. DOI: 10.1016/0749-6419(89)90001-6

[13] Vincent, Y., Bergheau, J.M. and Leblond, J.B. (2003). Viscoplastic behavior of steels during phase transformations. Comptes Rendu Mécanique, 331(9), pp. 587-594. DOI: 10.1016/S1631-0721(03)00147-5.

[14] Coret, M. and Combescure, A. (2002). A meso-model for the numerical simulation of the multiphasic behavior of materials under an isothermal loading (application to two low-carbon steels). Int. J. Mechanical Sciences, 44(9), pp. 1947-1963. hal.archives-ouvertes.fr/hal-01004844.

[15] Bouchouicha, B. (2007). Contribution à l'étude de la déchirure ductile et de la propagation des fissures en fatigue dans les joints soudes. Thèse de doctorat, Université de Sidi Belabbes, Algérie.

[16] Prashant, K. (2011), Elements of fracture mechanics, Tata McGraw Hill Publishing Company Limited, New Delhi, India.

[17] ASTM E1823 (2011), Standard Terminology Relating to Fatigue and Fracture Testing, American Society for Testing and Materials, USA.

[18] Vishal, M. (2016), Evaluation of the Fracture Parameters for SA - 516 Grade 70 Material, Mechanical Engineering Department, CGPIT, UTU, Bardoli, Surat, Gujarat, India. 13(6). pp. 38-45. doi: 10.9790/1684-1303033845.

[19] American Society Of Mechanical Engineering. (2013). ASME Boiler \& Pressure Vessel Code II Part D Materials Ferrous Material Specific, USA.

[20] Peijun, W. (2013). Properties of Steel at Elevated Temperatures, DOI: 10.1007/978-3-642-34393-3_3. https://www.researchgate.net/publication/284995632.

[21] Parmar, C., Gill, C. M., Hurrell, P.R. and Pellereau, B.M.E. (2014). Simulation of a Multi-pass Groove Weld and Clad Plate Using Abaqus 2D Weld GUI and Comparison with Measurements, SIMULIA UK Regional User Meeting.

[22] Lei, Y. (2008), Finite element crack closure analysis of a compact tension specimen. Int J Fatigue; 30. pp. 21-31. DOI: 10.1016/j.ijfatigue.2007.02.012.

[23] Griffith, A. A. (1924). The theory of rupture. Proceedings of the First International Congress of Applied Mechanics, Delpht, 63. p. 55. 